Check for updates

Cite this: RSC Adv., 2019, 9, 22597

\title{
Improving optoelectronic and charge transport properties of $D-\pi-D$ type diketopyrrolopyrrole- pyrene derivatives as multifunctional materials for organic solar cell applications $\dagger$
}

\begin{abstract}
Ruifa Jin, (D) *ab Kexin $\mathrm{Li}^{\mathrm{a}}$ and Xueli $\mathrm{Han}^{\mathrm{a}}$
A series of novel diketopyrrolopyrrole-pyrene-based molecules were designed for small molecule based organic solar cell (SMOSC) applications. Their electronic and charge transfer properties were investigated by applying the PBE0/6-31G(d,p) method. The absorption spectra were simulated using the TD-PBE0/6$31 \mathrm{G}(\mathrm{d}, \mathrm{p})$ method. The results showed that the frontier molecular orbital (FMO) energy levels, reorganization energy, the energetic driving force, and absorption spectra can be tuned by the introduction of different aromatic heterocyclic groups to the side of diketopyrrolopyrrole fragments' backbones. Additionally, the designed molecules possess suitable FMOs to match those of typical acceptors $\mathrm{PC}_{61} \mathrm{BM}$ and $\mathrm{PC}_{71} \mathrm{BM}$. Meanwhile, the designed molecules can act as good ambipolar charge transport materials in SMOSC applications. Meanwhile, the electron and hole reorganization energies of the designed molecules are smaller than those of the typical electron and hole transport materials, respectively. Moreover, the differences between electron and hole reorganization energies do not exceed $0.046 \mathrm{eV}$. Our results suggest that the designed molecules can act as promising candidates for donor and ambipolar charge transport materials in SMOSC applications.
\end{abstract}

Received 8th June 2019

Accepted 12th July 2019

DOI: $10.1039 / \mathrm{c} 9 \mathrm{ra04304g}$

rsc.li/rsc-advances
SMOSCs. To address this issue, an ideal small molecule used as the donor material should meet several requirements: (i) lower band gap and strong absorption for harvesting the solar light effectively, (ii) high hole mobility for fast charge-carrier transport to lead to high short circuit current $\left(J_{\text {sc }}\right.$ ), (iii) suitable frontier molecular orbitals (FMO) energy levels. A deep highest occupied molecular orbital (HOMO) energy of molecules ensures a high open circuit voltage $\left(V_{\mathrm{oc}}\right) \cdot{ }^{16-18}$ Meanwhile, another crucial parameter is the energetic driving force $\left(\Delta E_{\mathrm{L}-\mathrm{L}}\right)$. The $\Delta E_{\mathrm{L}-\mathrm{L}}$ is determined by the lowest unoccupied molecular orbital (LUMO) energy difference between the donor and acceptor. The $\Delta E_{\mathrm{L}-\mathrm{L}}$ plays a major role in enhancing charge transfer, which should exceed the binding energy ${ }^{19,20}$ Generally, the fullerene derivatives PC61BM or $\mathrm{PC}_{71} \mathrm{BM}\left([6,6]\right.$-phenyl- $\mathrm{C}_{61^{-}}$ (or $\mathrm{C}_{71}$ )-butyric acid methyl ester) were used as acceptors in OSCs. ${ }^{21,22}$ With the aim to enhance the PCE of SMOSCs, one efficient method is to design electron donor-acceptor (D-A) molecular structures. ${ }^{23,24}$ They can efficiently tune the FMOs energy levels through an intramolecular charge transfer, which leads to a narrow band gap, intense light absorption, and high PCEs. ${ }^{25-27}$ Additionally, the intermolecular stacking, film morphology, and charge transport properties can be determined by the type and length of side chains of $\mathrm{D}-\mathrm{A}$ molecular structures. ${ }^{28,29}$ It has been reported that a variety of structures, including A-D-A, D-A-D, D- $\pi-\mathrm{A}, \mathrm{D}-\pi-\mathrm{D}, \mathrm{A}-\pi-\mathrm{A}$, and $\mathrm{D}-\pi-\mathrm{A}-$ $\pi-\mathrm{D}$ were designed. ${ }^{30,31}$ Among the various $\mathrm{D}-\mathrm{A}$ type donor 
building blocks, diketopyrrolopyrrole (DPP)-based molecules have attracted great attention in terms of their outstanding features, such as good planarity, strong light absorption, high carrier mobility, good photochemical stability, and facile synthesis. $^{32,33}$ Moreover, pyrene is another promising donor building block. The pyrene derivatives can enhance the absorption due to their large aromatic hydrocarbon ring and planarity. ${ }^{\mathbf{3 4 , 3 5}}$ The planarity of molecules can improve the charge transport and interconnectivity. ${ }^{36}$ Therefore, the planar DPP and pyrene have combined each other to develop novel donor materials. ${ }^{37}$ Furthermore, it is worth noting that the charge mobility can been improved through introducing extended aromatic bridges to the DPP derivatives. ${ }^{38}$ Recently, DPP-based DDP-pyrene-DDP type molecules have been reported for use as donor material for SMOSCs. It was found that these molecules exhibited high hole mobility and PCEs for SMOSCs applications..$^{39,40}$

Taking into account these merits of DPP and pyrene derivatives mentioned above, we designed eight D-A-D type molecules as the acceptor materials for improving the efficiency of SMOSCs (Scheme 1). In order to study the influence of the DPP moiety on the optical, electronic, charge transfer properties, different aromatic heterocyclic groups have been introduced into the side of DPP in molecules. Applying density functional theory (DFT) approach, the properties of the designed molecules such as HOMO and LUMO energies ( $E_{\text {Hомо }}$ and $E_{\text {LUMO }}$ ), HOMO-LUMO gap $\left(E_{\mathrm{g}}\right), \Delta E_{\mathrm{L}-\mathrm{L}}$, the reorganization energy $(\lambda)$, adiabatic ionization potential (AIP) and electron affinity (AEA) were systematically investigated. The absorption spectra of the designed molecules were predicted using the time dependent DFT (TD-DFT) method. The charge transfer properties (reorganization energy, $\lambda$ ) were also simulated.

\section{Computational methods}

All the electronic structure calculations were carried out performed using the Gaussian 09 program suite. ${ }^{41}$ The molecular structures were optimized by the DFT method. Then the frequency calculations were performed at the same level of theory to confirm that all geometries are stable structures.
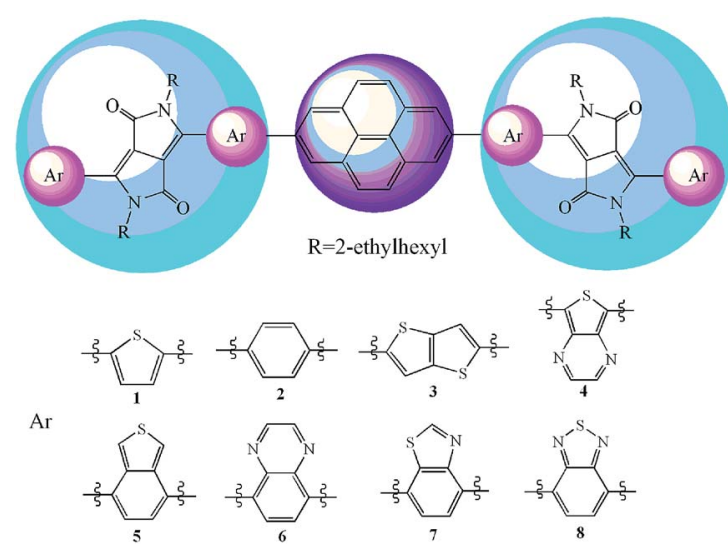

Scheme 1 Molecular structures of the investigated molecules.
Under the optimized structures, their absorption spectra were simulated at the TD-DFT level of theory. The all calculations were carried out with the $6-31 \mathrm{G}(\mathrm{d}, \mathrm{p})$ basis set. The solvent effects on the optical property in chloroform solution (dielectric constant: 4.7113) were also analyzed with the polarised continuum model (PCM). ${ }^{42}$ For the FMOs energy $E_{\mathrm{HOMO}}$ and $E_{\mathrm{LuMO}}$, the optimized geometries were used to obtain $E_{\mathrm{HOMO}}$. However, it is difficult to obtain the $E_{\text {LuMO }}$ since the virtual orbitals can not be described definitely by theoretical method. ${ }^{43}$ Therefore, the $E_{\mathrm{LUMO}}$ were be predicted by the sum of the $E_{\mathrm{HOMO}}$ and the first vertical excited energy. ${ }^{\mathbf{4 4 , 4 5}}$ It is important to choose an appropriate method in the theoretical investigations. In order to select reasonable method, six representative functionals, B3LYP, ${ }^{46} \mathrm{PBE}^{4},{ }^{47} \mathrm{LC}-\omega \mathrm{PBE},{ }^{48} \omega \mathrm{B} 97 \mathrm{XD},{ }^{49} \mathrm{M} 062 \mathrm{X},{ }^{50}$ and CAM-B3LYP ${ }^{51}$ were used to optimize the geometries of molecule 1, and then using the corresponding TD-DFT method, the absorption spectra were predicted in chloroform, respectively. The calculated data are shown in Table S1 in the ESI. $\dagger$ As showing Table $\mathrm{S} 1, \uparrow$ the calculated longest wavelengths of absorption ( $\left.\lambda_{\text {abs }}\right)$ using PBE0 $(583 \mathrm{~nm}$ ) approach compares very satisfactorily with the experimental result $(589 \mathrm{~nm}) .{ }^{39}$ Furthermore, in order to make further investigation of the validity of the selected approach, both PBE0 and B3LYP methods were also used to obtain the $E_{\mathrm{HOMO}}$ and $E_{\mathrm{LUMO}}$ of acceptors $\mathrm{PC}_{61} \mathrm{BM}$ and $\mathrm{PC}_{71} \mathrm{BM}$, and the calculated results are listed in Table S2 in the ESI. $\dagger$ The predicted $E_{\mathrm{HOMO}}$ and $E_{\mathrm{LUMO}}$ of $\mathrm{PC}_{61} \mathrm{BM}(-5.98$ and $-3.99 \mathrm{eV})$ and $\mathrm{PC}_{71} \mathrm{BM}(-5.92$ and $-3.82 \mathrm{eV})$ using PBE0 approach reproduce well the experimental data $(-6.00$ and $-3.80 \mathrm{eV},-6.00$ and $-3.95 \mathrm{eV}$, respectively). ${ }^{52,53}$ Comprehensively, the PBE0 method arises as the best choice for characterizing the systems studied in our work.

It is worth noting that the $\lambda$ plays an important role in determining the charge transfer. Usually, lower $\lambda$ value is beneficial for improving the charge transfer.$^{54,55}$ Meanwhile, the external $\lambda$ is much small compared with its internal $\lambda$ in organic condensed phases. ${ }^{5,57}$ Therefore, we only consider the internal $\lambda$ in this work. The electron and hole reorganization energy $\left(\lambda_{\mathrm{e}}\right.$ and $\lambda_{h}$ ) were be predicted by: ${ }^{58}$

$$
\begin{aligned}
& \lambda_{\mathrm{e}}=\left(E_{0}^{-}-E_{-}^{-}\right)+\left(E_{-}^{0}-E_{0}^{0}\right) \\
& \lambda_{\mathrm{h}}=\left(E_{0}^{+}-E_{+}^{+}\right)+\left(E_{+}^{0}-E_{0}^{0}\right)
\end{aligned}
$$

where, $E_{0}^{+}\left(E_{0}^{-}\right)$is the energy of the cation (anion) structure with the optimized neutral geometry molecule. $E_{+}^{0}\left(E_{-}^{0}\right)$ corresponds to the energy of the neutral structure with the optimized cation (anion) geometry structure. $E_{+}^{+}\left(E_{-}^{-}\right)$represents the energy of the cation (anion) calculated with the optimized cation (anion) structure, while $E_{0}^{0}$ is the energy of the neutral molecule at ground state. Furthermore, it is quite clear that the AIP and AEA play an important role in determining the charge transfer behavior for materials. In this work, the AIP is obtained by the energy difference between cation and neutral molecules. The AEA is determined by the energy difference between neutral and anion molecules. The $\lambda_{\mathrm{e}}, \lambda_{\mathrm{h}}$, AIP, and AEA were calculated using PBE0/6-31G(d,p) method. 


\section{Results and discussion}

\section{Match between the donor and acceptor}

It is noticeable that the electronic energy levels play important role roles to increase the PCE of SMOSCs. Small molecule donors should possess suitable energy levels with the acceptors to ensure efficient charge separation and to maximize the $J_{\mathrm{sc}}$ and $V_{\text {oc }}$. The deep HOMO and high LUMO levels are beneficial for improving the $V_{\mathrm{oc}}$ and for efficient exciton dissociation and charge separation, respectively. Moreover, small molecule donors should exhibit lower $E_{\mathrm{g}}$ to guarantee high harvest sunlight efficiency and enhance the $J_{\mathrm{sc}}$. Moreover, in order to ensure the efficient electron transfer, the $\Delta E_{\mathrm{L}-\mathrm{L}}$ should at least amount to $0.3 \mathrm{eV} .^{59,60}$ We choose $\mathrm{PC}_{61} \mathrm{BM}$ and $\mathrm{PC}_{71} \mathrm{BM}$ as acceptors in our work. Additionally, the explicit molecular orbital contributions from the individual fragments to the FMOs have been investigated by partial density of states (PDOS) analysis and the results are listed in Table 1 . With the aim of evaluating whether the FMOs energy of designed donors match with that of the acceptors, the $\Delta E_{\mathrm{L}-\mathrm{L}}$ are estimated. The calculated values of $\Delta E_{\mathrm{L}-\mathrm{L}}$ for 1-8 at the PBE0/6-31G(d,p) level are given in Table 2 . The results presented in Table 2 reveal that the $E_{\text {LUMO }}$ of 1-8 are positioned above those of $\mathrm{PC}_{61} \mathrm{BM}$ and $\mathrm{PC}_{71} \mathrm{BM}$, respectively. Meanwhile, the $\Delta E_{\mathrm{L}-\mathrm{L}}$ of 1-8 are 0.61-1.35 and $0.45-1.18 \mathrm{eV}$ for $\mathrm{PC}_{61} \mathrm{BM}$ and $\mathrm{PC}_{71} \mathrm{BM}$ as acceptors respectively, which are all beyond $0.3 \mathrm{eV}$. It indicates that the charge transfer from 1-8 to $\mathrm{PC}_{61} \mathrm{BM}$ and $\mathrm{PC}_{71} \mathrm{BM}$ efficiently. Additionally, the $E_{\mathrm{HOMO}}$ of 1-8 are larger than those of the $E_{\mathrm{LUMO}}$ of $\mathrm{PC}_{61} \mathrm{BM}$ and $\mathrm{PC}_{71} \mathrm{BM}$ about 1.07-1.40 and 1.24-1.57 eV, respectively (see Table S3 in the ESI $\dagger$ ). Both the sequences of difference values are $\mathbf{3}<\mathbf{1}<\mathbf{4}<\mathbf{7}<\mathbf{5}<\mathbf{6}<\mathbf{2}<\mathbf{8}$. It suggests that 1-8 possess suitable FMOs to match those of typical acceptors $\mathrm{PC}_{61} \mathrm{BM}$ and $\mathrm{PC}_{71} \mathrm{BM}$ for SMOSCs.

\section{Frontier molecular orbitals level and band gaps}

To gain insight into the influence of the FMO energies on the optical and electronic properties of the designed molecules, the contour plots of HOMOs and LUMOs have been examined (see Fig. 1). Inspection of the distribution of FMO reveals clearly that the HOMOs and LUMOs reveal $\pi$ characteristic and exhibit

Table 1 The HOMOs and LUMOs contributions (\%) of $1-8$ at the PBE0/6-31G(d,p) level

\begin{tabular}{|c|c|c|c|c|}
\hline \multirow[b]{2}{*}{ Molecules } & \multicolumn{2}{|c|}{ HOMOs } & \multicolumn{2}{|c|}{ LUMOs } \\
\hline & $\mathrm{PYR}^{a}$ & $\mathrm{DPP}^{b}$ & PYR & DPP \\
\hline 1 & 6.7 & 93.3 & 11.0 & 89.0 \\
\hline 2 & 3.8 & 96.2 & 6.2 & 93.8 \\
\hline 3 & 4.6 & 95.4 & 6.9 & 93.1 \\
\hline 4 & 8.6 & 91.4 & 9.9 & 90.1 \\
\hline 5 & 3.0 & 97.0 & 5.0 & 95.0 \\
\hline 6 & 1.8 & 98.2 & 3.9 & 96.1 \\
\hline 7 & 1.1 & 98.9 & 4.7 & 95.3 \\
\hline 8 & 3.4 & 96.6 & 4.9 & 95.1 \\
\hline
\end{tabular}

${ }^{a}$ PYR: pyrene moieties. ${ }^{b}$ DPP: diketopyrrolopyrrole moieties.
Table 2 Evaluation of calculated FMO energies, HOMO-LUMO gap $E_{\mathrm{g}}$, and energetic driving force $\Delta E_{\mathrm{L}-\mathrm{L}}$ for $1-8$ at the PBE0/6-31G(d,p) level

\begin{tabular}{lccccc}
\hline Molecules & $E_{\text {Hомо }}$ & $E_{\text {LUMO }}$ & $E_{\mathrm{g}}$ & $\Delta E_{\mathrm{L}-\mathrm{L}}{ }^{a}$ & $\Delta E_{\mathrm{L}-\mathrm{L}}{ }^{b}$ \\
\hline $\mathbf{1}$ & -5.11 & -2.93 & 2.18 & 1.06 & 0.89 \\
$\mathbf{2}$ & -5.33 & -2.71 & 2.62 & 1.28 & 1.11 \\
$\mathbf{3}$ & -5.06 & -2.98 & 2.08 & 1.01 & 0.84 \\
$\mathbf{4}$ & -5.18 & -3.38 & 1.80 & 0.61 & 0.44 \\
$\mathbf{5}$ & -5.23 & -2.82 & 2.41 & 1.17 & 1.00 \\
$\mathbf{6}$ & -5.27 & -3.00 & 2.27 & 0.99 & 0.82 \\
$\mathbf{7}$ & -5.19 & -2.64 & 2.55 & 1.35 & 1.18 \\
$\mathbf{8}$ & -5.39 & -3.37 & 2.02 & 0.62 & 0.45
\end{tabular}

${ }^{a}$ Energetic driving force for $\mathrm{PC}_{61} \mathrm{BM}$ as acceptor. ${ }^{b}$ Energetic driving force for $\mathrm{PC}_{71} \mathrm{BM}$ as acceptor.

strong delocalization features. For molecules 1-5, the electronic cloud distributions of the FMOs spread over the whole molecules with minor contributions from $\pi$-bridge fragment (pyrene). For molecules 6 and 7, the electronic cloud distributions of HOMOs are mainly delocalized on the one side DPP fragments, whereas the corresponding the LUMOs mainly reside at another side DPP fragments of molecules. For molecules 8, the HOMO is delocalized throughout the molecule, while the electron density of LUMO is mainly localized on the one side DPP fragment of molecule. This is favorable for the charge transfer across these conjugated donor materials. It suggests that the introduction of the extended aromatic bridges to the DPP derivatives significantly affect on the distributions of FMOs for the molecules.

The evaluations of $E_{\mathrm{HOMO}}, E_{\mathrm{LuMO}}$, and $E_{\mathrm{g}}$ for the designed molecules as well as $\mathrm{PC}_{61} \mathrm{BM}$ and $\mathrm{PC}_{71} \mathrm{BM}$ are plotted in Fig. 2 . From Fig. 2 one can find that the $E_{\text {номо values are in the order }}$ of $3>\mathbf{1}>\mathbf{4}>7>5>6>2>8$, and the sequence of $E_{\text {LUMO }}$ values is $7>2>5>1>3>6>8>4$. Clearly, comparing the $E_{\mathrm{HOMO}}$ and $E_{\mathrm{LuMO}}$ of 2-8 with those of 1, molecules 2, 5, and 7 can lower/ raise the $E_{\mathrm{HOMO}} / E_{\mathrm{LUMO}}$, whereas molecule 3 can raise/lower the $E_{\mathrm{HOMO}} / E_{\mathrm{LuMO}}$, respectively. On the other hand, molecules 4, 6, and 8 can lower both the $E_{\text {Hомо }}$ and $E_{\text {LUMO }}$, respectively. The trend of the $E_{\mathrm{g}}$ is $\mathbf{2}>\mathbf{7}>\mathbf{5}>\mathbf{6}>\mathbf{1}>\mathbf{3}>\mathbf{8}>\mathbf{4}$. It reveals that molecules $\mathbf{2 , 5}, \mathbf{6}$, and 7 can higher, whereas molecules $\mathbf{3}, \mathbf{4}$, and 8 can narrower the $E_{\mathrm{g}}$ than that of $\mathbf{1}$, respectively. The above results suggest that the $E_{\mathrm{HOMO}}, E_{\mathrm{LUMO}}$, and $E_{\mathrm{g}}$ can be tuned through the introduction of different aromatic heterocyclic groups to the molecules.

\section{Absorption and fluorescence spectra}

Table 3 collected the longest absorption wavelengths $\lambda_{\mathrm{abs}}$, oscillator strength $f$, and the main assignments of 1-8. The corresponding simulated absorption spectra are presented in Fig. 3. Inspection of Table 3 reveals clearly that the $\lambda_{\text {abs }}$ of molecules 1-5 correspond to the promotion of an electron from the HOMO $\rightarrow$ LUMO and HOMO-1 $\rightarrow$ LUMO+1 transitions, respectively. The $530 \mathrm{~nm}$ of molecule 6 essentially originates from the coupling of electronic transitions of HOMO $\rightarrow$ LUMO, HOMO-1 $\rightarrow$ LUMO, and HOMO $\rightarrow$ LUMO +1 . The shoulder at 
HOMO

LUMO

HOMO

LUMO
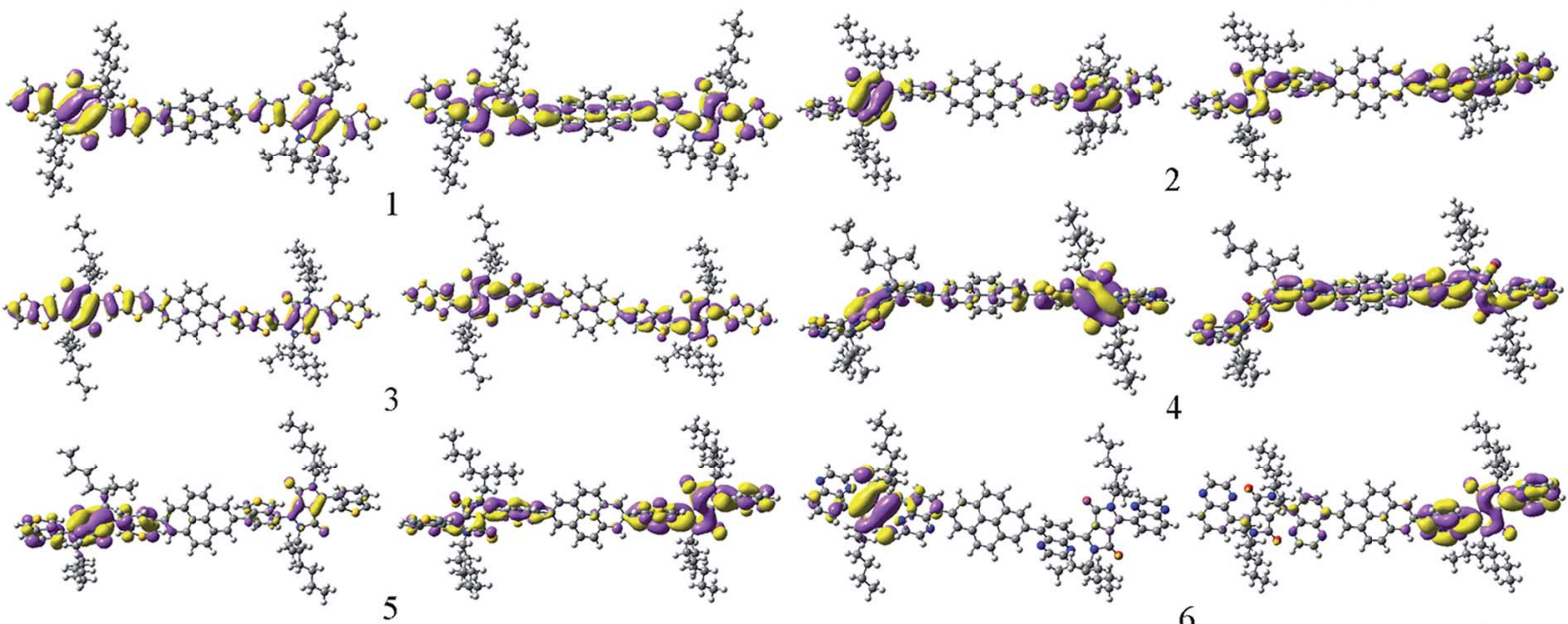

4
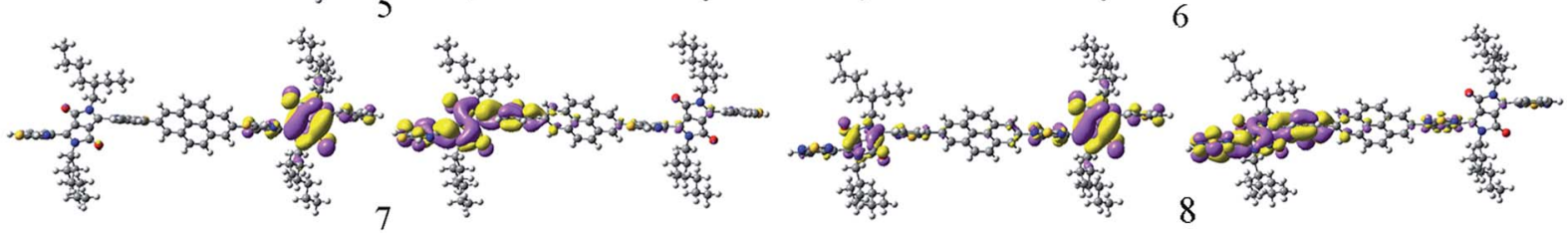

Fig. 1 The electronic density contours of the frontier orbital for the studied compounds at the PBE0/6-31G(d,p) level.

about 485 and $601 \mathrm{~nm}$ of molecules 7 and 8 are mainly derived from HOMO $\rightarrow$ LUMO, HOMO-1 $\rightarrow$ LUMO, and HOMO-1 $\rightarrow$ LUMO +1 transitions, respectively. Comparing the $\lambda_{\text {abs }}$ of molecules 2-8 with that of molecule 1 , molecules $3, \mathbf{4}$, and 8 exhibit bathochromic shifts 31, 98, and $18 \mathrm{~nm}$, respectively. However, molecules 2 and 5-7 show hypsochromic shifts 101, 59, 53, and $98 \mathrm{~nm}$, respectively. The $\lambda_{\text {abs }}$ sequence for 1-8 is $\mathbf{4}>\mathbf{3}>\mathbf{8}>\mathbf{1}>\mathbf{6}$ $>5>7>2$. It suggests that the $\lambda_{\text {abs }}$ of molecules 3,4 , and 8 exhibit bathochromic shifts, whereas the $\lambda_{\text {abs }}$ of molecules $2, \mathbf{5}$, 6, and 7 show hypsochromic shifts compared with that of molecule 1, respectively. Furthermore, the designed molecules show large $f$ values (0.90-2.33). Molecules 2-5 have slightly

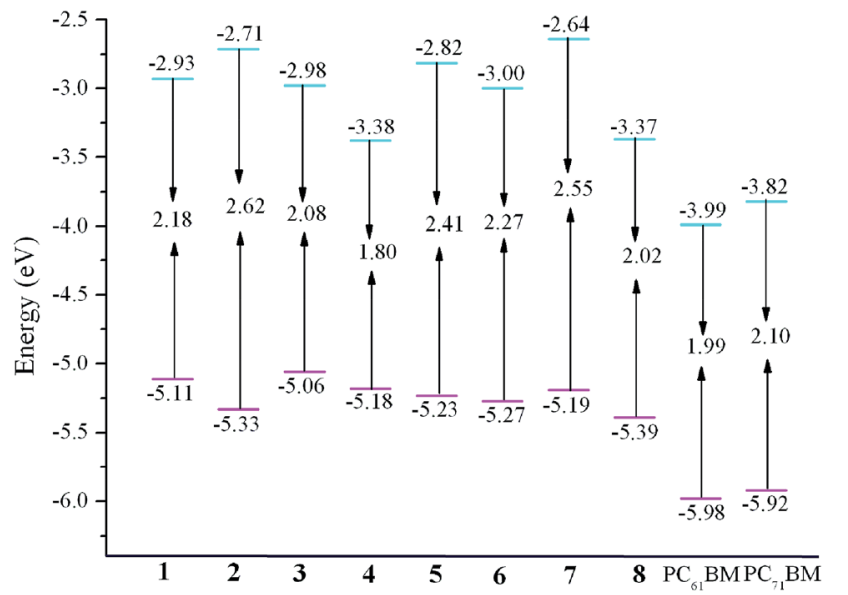

Fig. 2 Evaluation of calculated FMO energies for investigated molecules as well as $F M O$ energies for $\mathrm{PC}_{61} \mathrm{BM}$ and $\mathrm{PC}_{71} \mathrm{BM}$ at the PBEO/6$31 G(d, p)$ level. larger $f$ values than those of molecules 6-8, respectively. This indicates that molecules 2-5 exhibited slightly larger absorption intensity than those of molecules 6-8. Apparently, through the introduction of different aromatic heterocyclic groups to the side of DPP molecules backbones, their absorption spectrum of

Table 3 The electronic transition, absorption wavelengths $\lambda_{\text {abs }}$ (in $\mathrm{nm}$ ), the oscillator strength $f$, and main assignments (coefficient) of 1-8 in chloroform at the TD-PBE0/6-31G(d,p)//PBE0/6-31G(d,p) level, along with available experimental data

\begin{tabular}{|c|c|c|c|}
\hline Molecules & $\lambda_{\mathrm{abs}}$ & $f$ & Assignment \\
\hline 1 & 583 & 2.33 & $\begin{array}{l}\mathrm{H} \rightarrow \mathrm{L}(0.66) \\
\mathrm{H}-1 \rightarrow \mathrm{L}+1(0.25)\end{array}$ \\
\hline 2 & 482 & 1.37 & $\begin{array}{l}\mathrm{H} \rightarrow \mathrm{L}(0.58) \\
\mathrm{H}-1 \rightarrow \mathrm{L}+1(0.30)\end{array}$ \\
\hline 3 & 614 & 2.93 & $\begin{array}{l}\mathrm{H} \rightarrow \mathrm{L}(0.62) \\
\mathrm{H}-1 \rightarrow \mathrm{L}+1(0.32)\end{array}$ \\
\hline 4 & 681 & 1.59 & $\begin{array}{l}\mathrm{H} \rightarrow \mathrm{L}(0.64) \\
\mathrm{H}-1 \rightarrow \mathrm{L}+1(0.27)\end{array}$ \\
\hline 5 & 524 & 1.66 & $\begin{array}{l}\mathrm{H} \rightarrow \mathrm{L}(0.49) \\
\mathrm{H}-1 \rightarrow \mathrm{L}+1(0.33)\end{array}$ \\
\hline 6 & 530 & 1.00 & $\begin{array}{l}\mathrm{H} \rightarrow \mathrm{L}(-0.36) \\
\mathrm{H}-1 \rightarrow \mathrm{L}(0.44) \\
\mathrm{H} \rightarrow \mathrm{L}+1(-0.32)\end{array}$ \\
\hline 7 & 485 & 0.93 & $\begin{array}{l}\mathrm{H} \rightarrow \mathrm{L}(0.33) \\
\mathrm{H}-1 \rightarrow \mathrm{L}(0.61) \\
\mathrm{H}-1 \rightarrow \mathrm{L}+1(0.13)\end{array}$ \\
\hline 8 & 601 & 0.90 & $\begin{array}{l}\mathrm{H} \rightarrow \mathrm{L}(0.56) \\
\mathrm{H}-1 \rightarrow \mathrm{L}(-0.36) \\
\mathrm{H}-1 \rightarrow \mathrm{L}+1(0.22)\end{array}$ \\
\hline
\end{tabular}

$\operatorname{Exp}^{a} \quad 589$

${ }^{a}$ Experimental results of $\mathbf{1}$ were taken from ref. 39. 


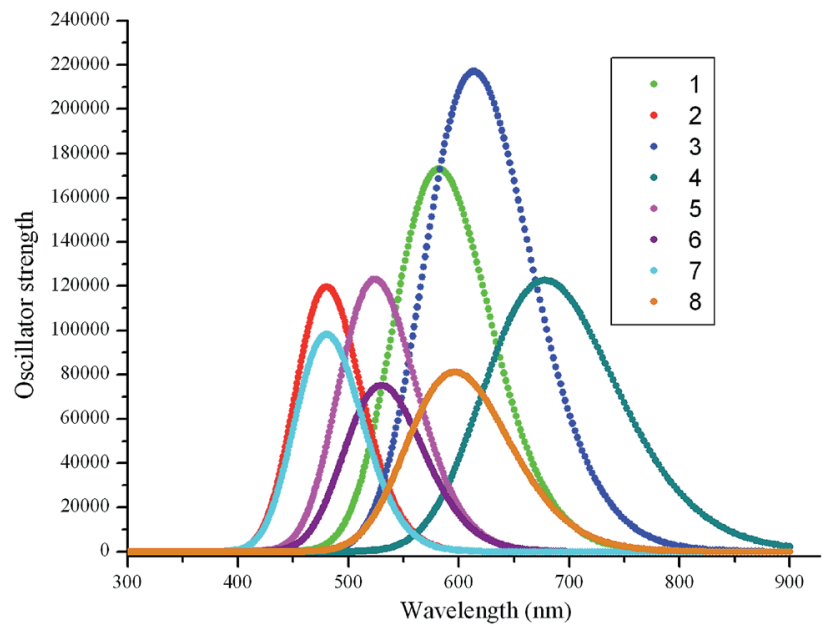

Fig. 3 The calculated absorption spectra of the investigated molecules (value of full width at half maximum is $3000 \mathrm{~cm}^{-1}$ ).

the studied molecules can be tuned effectively. With the above considerations, these molecules can act as donor material with strong absorption spectra for SMOSCs.

\section{Charge transfer properties}

It is commonly known that the AIP, AEA, and $\lambda$ are three key parameters that determine the charge transfer property. The AIP and AEA are good descriptors to estimate the energy barrier for the injection of holes and electrons, respectively. The $\lambda$ is the extent to estimate the ability to carry the charge in solid. Usually, lower AIP and higher AEA are favorable for better charge transport ability for hole and electron, respectively. ${ }^{61,62}$ For $\lambda$, the lower $\lambda_{\mathrm{e}}$ and $\lambda_{\mathrm{h}}$ are beneficial for enhancement the electron and hole transfer rate, respectively. ${ }^{54,55}$

The predictions of AIP, AEA, $\lambda_{\mathrm{h}}$, and $\lambda_{\mathrm{e}}$ of the designed molecules are summarized in Table 4 . It is clear that the AIP are in the order of $8>2>6>5>7>1>4>3$. The AIP of molecules 2 and 5-8 are larger, whereas the AIP of molecules 3 and $\mathbf{4}$ are smaller than that of molecule $\mathbf{1}$, respectively. Namely, comparing the AIP of 2-8 with that of $\mathbf{1}$, molecules $\mathbf{2}$ and 5-8 can raise the AIP, while molecules 3 and 4 can lower the AIP, respectively. At the same time, the AEA is in the order of $4>8>3$ $>\mathbf{1}>6>5>2>7$. Obviously, comparing the AEA of molecules 2-

Table 4 Calculated molecular $\lambda_{\mathrm{e}}, \lambda_{\mathrm{h}}, \mathrm{AIP}, \mathrm{AEA}$ and $\eta$ (all in eV) of 1-8 at the PBE0/6-31G(d,p) level

\begin{tabular}{llllll}
\hline Molecules & $\lambda_{\mathrm{h}}$ & $\lambda_{\mathrm{e}}$ & AIP & AEA & $\eta$ \\
\hline $\mathbf{1}$ & 0.187 & 0.166 & 5.716 & 2.008 & 1.854 \\
$\mathbf{2}$ & 0.207 & 0.213 & 5.937 & 1.746 & 2.096 \\
$\mathbf{3}$ & 0.169 & 0.123 & 5.603 & 2.108 & 1.747 \\
$\mathbf{4}$ & 0.232 & 0.198 & 5.715 & 2.382 & 1.667 \\
$\mathbf{5}$ & 0.207 & 0.210 & 5.789 & 1.826 & 1.981 \\
$\mathbf{6}$ & 0.214 & 0.197 & 5.877 & 1.935 & 1.971 \\
7 & 0.214 & 0.259 & 5.780 & 1.694 & 2.051 \\
$\mathbf{8}$ & 0.191 & 0.167 & 5.981 & 2.286 & 1.848
\end{tabular}

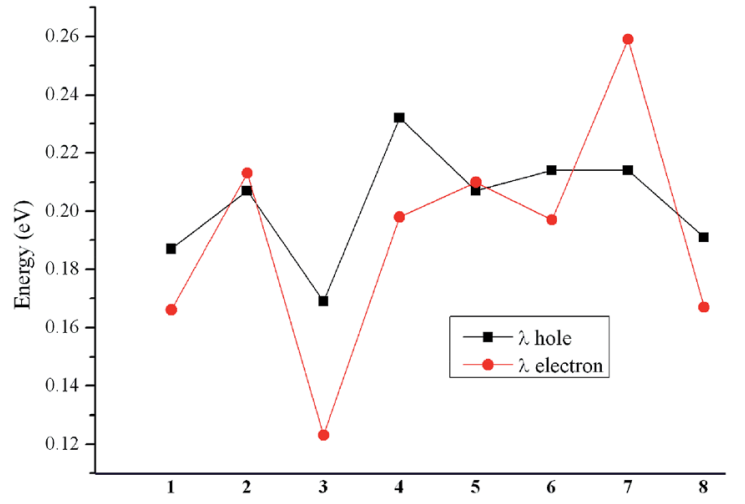

Fig. 4 Graphical representation of $\lambda_{e}$ and $\lambda_{h}$ calculated at the PBEO/6$31 \mathrm{G}(\mathrm{d}, \mathrm{p})$ level of theory.

8 with that of molecule 1 , molecules 3,4 , and 8 increase the AEA, whereas molecules 2 and 5-7 decrease the AEA, respectively. It is noticeable that the introduction of different aromatic heterocyclic groups to the molecules affects both their AIP and AEA values.

A graphical representation of $\lambda_{\mathrm{h}}$ and $\lambda_{\mathrm{e}}$ has been illustrated in Fig. 4 to represent the results more clearly. Generally, Alq3 (tris(8-hydroxyquinolinato)aluminum(III), $\lambda_{\mathrm{e}}=0.276 \mathrm{eV}$ ) and TPD ( $N, N^{\prime}$-diphenyl- $N, N^{\prime}$-bis(3-methlphenyl)-(1,1'-biphenyl)$4,4^{\prime}$-diamine, $\left.\lambda_{\mathrm{h}}=0.290 \mathrm{eV}\right)$ are taken as the typical electron and hole transport materials, respectively ${ }^{63,64}$ Apparently, the $\lambda_{\mathrm{e}}$ and $\lambda_{\mathrm{h}}$ of the designed compounds are much smaller than those of Alq3 and TPD, respectively. It indicates that both the electron and hole transfer rates of 1-8 might be higher than those of Alq3 3 and TPD, respectively. The decreasing sequence of $\lambda_{\mathrm{h}}$ is $\mathbf{4}>$ $6 \approx 7>2 \approx 5>8>1>3$, and the values of $\lambda_{\mathrm{e}}$ are in the following order: $7>2>5>4>6>8>1>3$. Apparently, comparing the $\lambda_{\mathrm{h}}$ and $\lambda_{\mathrm{e}}$ of molecule 2-8 with those of $\mathbf{1}$, molecules $\mathbf{2 , 4 - 8}$ can increase both $\lambda_{h}$ and $\lambda_{e}$, whereas compound 3 can decrease both $\lambda_{\mathrm{h}}$ and $\lambda_{\mathrm{e}}$, respectively. Additionally, molecule 3 has both the smallest $\lambda_{\mathrm{h}}$ and $\lambda_{\mathrm{e}}$ values, indicating that molecule 3 has the largest hole and electron transport rates among the investigated molecules. Moreover, the differences between $\lambda_{\mathrm{e}}$ and $\lambda_{\mathrm{h}}$ values of 1-8 do not exceed $0.046 \mathrm{eV}$. It indicates that they exhibit better hole- and electron-transporting balance. Accordingly, these molecules can act as nice ambipolar charge transport materials for SMOSCs. Therefore, these molecules can be used as good candidates for ambipolar charge transport materials under the proper operating conditions.

\section{Conclusions}

In this article, we design a series of novel diketopyrrolopyrrolepyrene-based molecules as the acceptor materials for SMOSCs applications. The optical, electronic, and charge transporting properties were investigated by applying DFT and TD-DFT methods. The parameters such as $\Delta E_{\mathrm{L}-\mathrm{L}}, \lambda$, AIP, and AEA were calculated to preliminarily evaluate the performance of the solar cell. The results show that the $E_{\text {Hомо }}, E_{\mathrm{LUMO}}, E_{\mathrm{g}}, \Delta E_{\mathrm{L}-\mathrm{L}}$, AIP, $\mathrm{AEA}$, and $\lambda$ can be tuned through the introduction of different 
aromatic heterocyclic groups to the molecules. The absorption spectra were also simulated. Our results suggest that the designed molecules possess suitable FMOs to match those of typical acceptors $\mathrm{PC}_{61} \mathrm{BM}$ and $\mathrm{PC}_{71} \mathrm{BM}$. Additionally, they can be used as ambipolar charge transport materials for SMOSCs.

\section{Conflicts of interest}

There are no conflicts to declare.

\section{Acknowledgements}

Financial supports from the NSFC (No. 21563002) are gratefully acknowledged.

\section{Notes and references}

1 L. Lu, T. Zheng, Q. Wu, A. M. Schneider, D. Zhao and L. Yu, Chem. Rev., 2015, 115, 12666-12731.

2 W. Cao and J. Xue, Energy Environ. Sci., 2014, 7, 2123-2144.

3 K. Mazzio and C. K. Luscombe, Chem. Soc. Rev., 2015, 44, 7890.

$4 \mathrm{~K}$. H. Hendriks, G. H. L. Heintges, V. S. Wienk, M. M. Gevaerts and R. A. J. Janssen, Angew. Chem., Int. Ed., 2013, 52, 8341-8344.

5 L. Ye, S. Zhang, L. Huo, M. Zhang and J. Hou, Acc. Chem. Res., 2014, 47, 1595-1603.

6 Q. R. Yin, J. S. Miao, Z. Wu, Z. F. Chang, J. L. Wang, H. B. Wu and Y. Cao, J. Mater. Chem. A, 2015, 3, 11575-11586.

7 H. Yao, L. Ye, H. Zhang, S. Li, S. Zhang and J. Hou, Chem. Rev., 2016, 116, 7397-7457.

8 Y. Chen, X. Wan and G. Long, Acc. Chem. Res., 2013, 46, 26452655.

9 A. Mishra and P. Bäuerle, Angew. Chem., Int. Ed., 2012, 51, 2020-2067.

10 Y. Lin, Y. Li and X. Zhan, Chem. Soc. Rev., 2012, 41, 42454272.

11 B. Kan, M. Li, Q. Zhang, F. Liu, X. Wan, Y. Wang, W. Ni, G. Long, X. Yang, H. Feng, Y. Zuo, M. Zhang, F. Huang, Y. Cao, T. P. Russell and Y. Chen, J. Am. Chem. Soc., 2015, 137, 3886-3893.

12 J. H. Kim, C. E. Song, N. Shin, H. Kang, S. Wood, I. N. Kang, B. Kim, B. Kim, J. S. Kim, W. S. Shin and D. H. Hwang, ACS Appl. Mater. Interfaces, 2013, 5, 12820-12831.

13 Z. He, B. Xiao, F. Liu, H. Wu, Y. Yang, S. Xiao, C. Wang,

T. P. Russell and Y. Cao, Nat. Photonics, 2015, 9, 174-179.

14 Y. Lin and X. Zhan, Acc. Chem. Res., 2016, 49, 175-183.

15 D. Ni, B. Zhao, T. Shi, S. Ma, G. Tu and H. Wu, ACS Macro Lett., 2013, 2, 621-624.

16 J. Li, K. H. Ong, S. L. Lim, G. M. Ng, H. S. Tan and Z. K. Chen, Chem. Commun., 2011, 47, 9480-9482.

17 J. E. Coughlin, Z. B. Henson, G. C. Welch and G. C. Bazan, Acc. Chem. Res., 2014, 47, 257-270.

18 Y. Huang, M. Zhang, H. Chen, F. Wu, Z. Cao, L. Zhang and S. Tan, J. Mater. Chem. A, 2014, 2, 5218-5223.

19 M. Knupfer, Appl. Phys. A, 2003, 77, 623-626.
20 I. Hill, A. Kahn, Z. Soos and R. Pascal Jr, Chem. Phys. Lett., 2000, 327, 181-188.

21 C. He, Q. G. He, X. D. Yang, G. L. Wu, C. H. Yang, F. L. Bai, Z. G. Shuai, L. X. Wang and Y. F. Li, J. Phys. Chem. C, 2007, 111, 8661-8666.

22 M. Lenes, G. A. H. Wetzelaer, F. B. Kooistra, S. C. Veenstra, J. C. Hummelen and P. W. M. Blom, Adv. Mater., 2008, 20, 2116-2119.

23 M. Cheng, C. Chen, X. Yang, J. Huang, F. Zhang, B. Xu and L. Sun, Chem. Mater., 2015, 27, 1808-1814.

24 E. Wang, L. Hou, Z. Wang, S. Hellström, F. Zhang, O. Inganäs and M. R. Andersson, Adv. Mater., 2010, 22, 5240-5244.

25 A. Tang, C. Zhan and J. Yao, Chem. Mater., 2015, 27, 47194730.

26 E. Wang, W. Mammo and M. R. Andersson, Adv. Mater., 2014, 26, 1801-1826.

27 P. Zhou, D. Dang, M. Xiao, Q. Wang, J. Zhong, H. Tan, Y. Pei, R. Yang and W. Zhu, J. Mater. Chem. A, 2015, 3, 10883-10889.

28 H. Qin, L. Li, F. Guo, S. Su, J. Peng, Y. Cao and X. Peng, Energy Environ. Sci., 2014, 7, 1397-1401.

29 S. Chen, L. Xiao, X. Zhu, X. Peng, W. K. Wong and W. Y. Wong, Chem. Commun., 2015, 51, 14439-14442.

30 Y. Li, R. G. Clevenger, L. Jin, K. V. Kilway and Z. Peng, J. Mater. Chem. C, 2014, 2, 7180-7183.

31 J. L. Wang, F. Xiao, J. Yan, Z. Wu, K. K. Liu, Z. F. Chang, R. B. Zhang, H. Chen, H. B. Wu and Y. Cao, Adv. Funct. Mater., 2016, 26, 1803-1812.

32 K. Gao, J. Miao, L. Xiao, W. Deng, Y. Kan, T. Liang, C. Wang, F. Huang, J. Peng and Y. Cao, Adv. Mater., 2016, 28, 47274733.

33 J. H. Liu, B. Walker, A. Tamayo, Y. Zhang and T. Q. Nguyen, Adv. Funct. Mater., 2013, 23, 47-56.

34 X. Liu, G. Luo, X. Cai, H. Wu, S. J. Su and Y. Cao, RSC Adv., 2015, 5, 83155-83163.

35 J. Mei, K. R. Graham, R. Stalder, S. P. Tiwari, H. Cheun, J. Shim, M. Yoshio, C. Nuckolls, B. Kippelen, R. K. Castellano and J. R. Reynolds, Chem. Mater., 2011, 23, 2285-2288.

36 O. P. Lee, A. T. Yiu, P. M. Beaujuge, C. H. Woo, T. W. Holcombe, J. E. Millstone, J. D. Douglas, M. S. Chen and J. M. Fréchet, Adv. Mater., 2011, 23, 5359-5363.

37 K. A. Mazzio, M. J. Yuan, K. Okamoto and C. K. Luscombe, ACS Appl. Mater. Interfaces, 2011, 3, 271-278.

38 Q. Wang, J. J. van Franeker, B. J. Bruijnaers, M. M. Wienk and R. A. J. Janssen, J. Mater. Chem. A, 2016, 4, 10532-10541.

39 H. Huang, L. Xiao, B. Yang, T. Lai, L. Zhang, K. Gao, X. Peng and Y. Cao, RSC Adv., 2016, 6, 59218-59225.

40 J. Chen, L. Duan, M. Xiao, Q. Wang, B. Liu, H. Xia, R. Yang and W. Zhu, J. Mater. Chem. A, 2016, 4, 4952-4961.

41 M. J. Frisch, G. W. Trucks, H. B. Schlegel, G. E. Scuseria, M. A. Robb, J. R. Cheeseman, G. Scalmani, V. Barone, B. Mennucci, G. A. Petersson, H. Nakatsuji, M. Caricato, X. Li, H. P. Hratchian, A. F. Izmaylov, J. Bloino, G. Zheng, J. L. Sonnenberg, M. Hada, M. Ehara, K. Toyota, R. Fukuda, J. Hasegawa, M. Ishida, T. Nakajima, Y. Honda, O. Kitao, H. Nakai, T. Vreven, J. A. Montgomery Jr, 
J. E. Peralta, F. Ogliaro, M. Bearpark, J. J. Heyd, E. Brothers, K. N. Kudin, V. N. Staroverov, T. Keith, R. Kobayashi, J. Normand, K. Raghavachari, A. Rendell, J. C. Burant, S. S. Iyengar, J. Tomasi, M. Cossi, N. Rega, J. M. Millam, M. Klene, J. E. Knox, J. B. Cross, V. Bakken, C. Adamo, J. Jaramillo, R. Gomperts, R. E. Stratmann, O. Yazyev, A. J. Austin, R. Cammi, C. Pomelli, J. W. Ochterski, R. L. Martin, K. Morokuma, V. G. Zakrzewski, G. A. Voth, P. Salvador, J. J. Dannenberg, S. Dapprich, A. D. Daniels, O. Farkas, J. B. Foresman, J. V. Ortiz, J. Cioslowski, and D. J. Fox, Gaussian 09, Gaussian, Inc., Wallingford, CT, 2009. 42 J. P. Cornard and C. Lapouge, J. Phys. Chem. A, 2006, 110, 7159-7166.

43 J. Wu, Y. H. Kan, Y. Wu and Z. M. Su, J. Phys. Chem. C, 2013, 117, 8420-8428.

44 J. Ku, Y. Lansac and Y. H. Jang, J. Phys. Chem. C, 2011, 115, 21508-21516.

45 G. Zhang and C. B. Musgrave, J. Phys. Chem. A, 2007, 111, 1554-1561.

46 C. Lee, W. Yang and R. G. Parr, Phys. Rev. B, 1988, 37, 785789.

47 C. Adamo and V. Barone, J. Chem. Phys., 1999, 110, 61586170.

48 Y. Tawada, T. Tsuneda, S. Yanagisawa, T. Yanai and K. Hirao, J. Chem. Phys., 2004, 120, 8425-8433.

49 J. D. Chai and M. Head-Gordon, Phys. Chem. Chem. Phys., 2008, 10, 6615-6620.

50 Y. Zhao and D. G. Truhlar, Theor. Chem. Acc., 2008, 120, 215241.
51 T. Yanai, D. P. Tew and N. C. Handy, Chem. Phys. Lett., 2004, 393, 51-57.

52 I. Jeon, C. Delacou, T. Nakagawa and M. Y. Yutaka, Chem.Asian J., 2016, 11, 1268-1272.

53 M. Chandrasekharam, M. A. Reddy, K. Ganesh, G. D. Sharma, S. P. Singh and J. L. Rao, Org. Electron., 2014, 15, 2116-2125.

54 R. A. Marcus, Rev. Mod. Phys., 1993, 65, 599-610.

55 R. A. Marcus, Annu. Rev. Phys. Chem., 1964, 15, 155-196.

56 S. Di Motta, E. Di Donato, F. Negri, G. Orlandi, D. Fazzi and C. Castiglioni, J. Am. Chem. Soc., 2009, 131, 6591-6595.

57 D. P. McMahon and A. Trois, J. Phys. Chem. Lett., 2010, 1, 941-946.

58 M. E. Köse, W. J. Mitchell, N. Kopidakis, C. H. Chang, S. E. Shaheen, K. Kim and G. Rumbles, J. Am. Chem. Soc., 2007, 129, 14257-14270.

59 M. C. Scharber, D. Wuhlbacher, M. Koppe, P. Denk, C. Waldauf, A. J. Heeger and C. L. Brabec, Adv. Mater., 2006, 18, 789-794.

60 J. L. Brédas, D. Beljonne, V. Coropceanu and J. Cornil, Chem. Rev., 2004, 104, 4971-5004.

61 C. C. Liu, S. W. Mao and M. Y. Kuo, J. Phys. Chem. C, 2010, 114, 22316-22321.

62 G. Li, R. Zhu and Y. Yang, Nat. Photonics, 2012, 6, 153-161. 63 B. C. Lin, C. P. Cheng, Z. Q. You and C. P. Hsu, J. Am. Chem. Soc., 2005, 127, 66-67.

64 N. E. Gruhn, D. A. da Silva Filho, T. G. Bill, M. Malagoli, V. Coropceanu, A. Kahn and J. L. Bredas, J. Am. Chem. Soc., 2002, 124, 7918-7919. 